\title{
Drugged-driving: putting the brakes on pot use
}

Part I: Marijuana use affects driving

$\mathrm{W}$

ith the growing use of medicinal marijuana, lower penalties for possession and the movement to legalize pot, experts say Canada needs better screening procedures and smarter laws to reduce the prevalence of drug-impaired driving - and the deaths that result.

In $2008,37 \%$ of drivers who died in vehicle crashes tested positive for one or more psychoactive substances other than alcohol. This is an increase of $7 \%$ from 2000, according to the Canadian Centre on Substance Abuse (CCSA), and nearly equal to the $41 \%$ of fatally injured drivers who tested positive for alcohol. In reality, the percentage of drivers using psychoactive substances is probably much higher, because fewer than half of the 17237 people who died in crashes from 2000-2008 were even tested for drugs. Cannabis and depressants, such as Valium, were the most common psychoactive substances.

Despite the danger of drug-impaired driving, enforcers and scientists agree that implementing laws on marijuana use is complicated because of the variable effects of the drug and difficulties defining a legal limit. Yet, other countries and jurisdictions have seemingly solved these issues.

In this series of articles, $C M A J$ will look at how marijuana affects driving, difficulties with screening and the struggle to clarify laws.

The CCSA estimates that 15 million trips were made by drivers in Canada after using marijuana in 2013. This is an alarming frequency, says Robert Solomon, professor of law at Western University. He is particularly worried about young people, who are already at high risk for motor vehicle crashes. "I am concerned that we are going to see a significant increase in drug-related crashes."

In a 2011 Canadian addiction survey, $12 \%$ of those aged 15-24 reported driving within two hours of using cannabis, compared with $10 \%$ who reported driving under the influence of alcohol.

Adults are using too. In a roadside

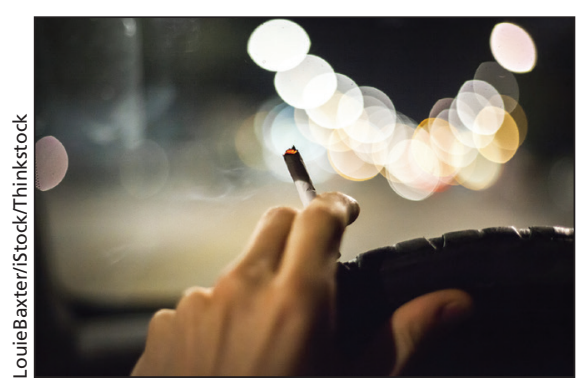

Driving under the influence of marijuana can be dangerous.

survey of 1197 drivers in British Columbia, cannabis use was reported among all age groups 16-55 and older.

Solomon says that Canadians' seemingly lax attitude stems from a lack of awareness of the risks and a lack of fear of being charged and convicted (which will be addressed later in this series).

"People who smoke cannabis and drive say it makes them a better driver," says Dr. Douglas Beirness, a senior research associate at the CCSA.

A 2012 review on driving under the influence of cannabis in Clinical Chemistry indicates that it impairs higher-order planning and execution of complex tasks, both of which affect safe driving. And though people say marijuana helps them concentrate and drive slower, making them a better driver, Beirness says they can concentrate only on one thing at a time. "They are unable to process a lot of information coming at them."

Impairment includes weaving in and out of lanes, problems maintaining position and variability in driving performance, says Beirness. These problems can last up to three hours after use.

Although it has been clear for 20 years that cannabis affects cognitive and motor tasks involved in safe driving, Dr. Robert Mann a senior scientist at the Centre for Addiction and Mental Health says it is difficult to establish a dose-effect relationship.

"We cannot be as clear about the likely effects of smoking $x$ number of joints as we can about the likely effects of $x$ drinks," he said. - Dane Wanniarachige, $C M A J$

CMAJ 2015. DOI:10.1503/cmaj.109-4993 